\title{
Development of a System of Standard Designs in Industrial Construction
}

\author{
Dmitriy Silka ${ }^{1, *}$ and Andrey Butyrin ${ }^{2}$ \\ ${ }^{1}$ Russian Presidential Academy of the National Economy and Public Administration, 82 Vernadsky \\ Ave., Moscow, 119571, Russia \\ ${ }^{2}$ Moscow State University of Civil Engineering, 26 Yaroslavskoye Shosse, 129377, Moscow, Russia
}

\begin{abstract}
The use of standard designs in construction is a topical subject of research within the frame of project management. Construction projects, especially industrial construction ones, are characterized by a great diversity of design and other solutions. Just about any new project produces new ways of resolving issues and involves looking for optimum constructive, planning, and other solutions. There arises the need to coordinate all parts of the work with the client, although essentially there is nothing particularly novel about the project, as many of the issues were already resolved in past activity. Quite naturally, many construction companies will look for tried-and-true solutions and strive for the unification and standardization of design work. This paper describes a set of tools for implementing a system of standard designs and proposes a set of ways to achieve one's key design objectives.
\end{abstract}

\section{Introduction}

The construction of any building or structure is carried out as per a pre-developed document referred to as a design. Designing is the first stage in construction, and is a highly important one. A design is a collection of graphic and textual materials that incorporate solutions on technology and equipment for a future enterprise or building, architecturalplanning and constructive solutions, technical and financial viability assessments, cost estimates, and all relevant explanatory notes.

Design documentation, adopted in an established manner, is a set of documental materials required for carrying out construction work, which includes drawings, analyses, layouts, viability assessments, cost estimates, etc. To optimize work on preparing design documentation, many research organizations and commercial enterprises are working on the development of a system of standard designs intended to help re-use the best solutions (Taberko et al., 2019; Sorokin \& Sidorkina, 2018).

In Russia, standardization and unification began to be implemented in industrial construction at the time of the first five-year plan (1928-1932), the first stage in the industrialization of the country. At that time, it was recommended that production facilities in the metallurgical and machine-building industries use a span that is a multiple of three meters and use a spacing that is a multiple of six meters. In 1939, based on sizes that are a multiple of three meters, the nation's construction authorities developed standard units

\footnotetext{
*Corresponding author: w220@yandex.ru
} 
(sections) in single-storey industrial buildings and compiled albums of standard parts.

In 1955, the USSR's State Committee for Construction introduced a single system for assigning key construction parameters for buildings in most sectors of industry, with dimensional layouts for buildings developed. These layouts provided a building's dimensions in plan, its longitudinal and cross sections, the height of its spaces, and the type and load capacity of in-plant transportation equipment. In 1957, the country's construction authorities released the first catalogue of unified precast reinforced concrete structures for industrial construction. In 1962, the nation began to design buildings from unified standard sections and spans.

The upsurge in residential construction witnessed in the Soviet Union in the early 1960s was possible mainly thanks to the industrialization of construction, which, in turn, was predicated on the standardization of buildings, unification and standardization of construction parts, and development and increasing specialization of the construction industry and the building materials industry.

Thus, standard designs were intended for multiple use. Designs of this kind used to be employed in erecting schools, hostels, industrial buildings, and agricultural facilities. In this case, the designer's job was mainly to apply a standard design to a specific job site, which helped significantly to accelerate the construction work and make it cheaper.

The process of creating standard solutions continues to this day, and requires developing new approaches and tools.

\section{Literature review}

Being a subject of vital significance, issues related to design and the efficiency of the design process have been explored by numerous researchers. Work on streamlining the design process is currently being conducted by various academic and educational organizations, as well as research divisions in various industrial and industrial-construction companies.

A research study by V.K. Demchenkov looks into the history of the emergence and development of the principles of standard design in construction and their economic and industrial significance (Demchenkov, 2020). The researcher discusses the trend of shifting to standard design in the context of striving to achieve priority objectives for the development of the construction sector for the period through to 2030. The work's scientific-practical value lies in that it identifies the prospects for and makes the case for the importance of continuing work in the area of design standardization and unification despite the uniqueness and complexity of construction projects growing with the passage of time.

Scholar I.V. Berezhnaya has addressed the design of a decision tree in the design process (Berezhnaya, 2020). The researcher provides a brief description of a decision tree and furnishes figures illustrating the entire process of determining a suitable standard algorithm for the design team to follow. The idea is help lay a foundation for the creation of a system of design in companies within the construction sector and other sectors.

Significant potential is offered today by BIM (building information modeling) solutions (Baldin, Korolev, \& Kutuzov, 2020). Computer modeling is based on a wide range of references, databases, and other auxiliary materials that are employed for the development of ready-made design documents. The use of standardized solutions within the frame of BIM is key to the successful achievement of results. A well-tuned BIM system can ensure a high level of joint work among specialists representing various disciplines, and it can reduce the number of errors significantly. It can help create construction designs and engineering systems of any level of complexity. Based on the models designed, the specialists can work out an effective construction technology and determine the precise amount of materials required for the project. 
Another noteworthy research study involving the use of cutting-edge information technology, a work by scholar E.A. Petrakova, is about the development of a 3D parametric model (Petrakova, 2020). The researcher views this as a creative process, as one and the same 3D model can be constructed in different ways. The proposed methodology for the effective design of parametric 3D models using the internal capabilities of CAD software can be used without engaging programming languages (macros). The use of the techniques and recommendations examined in the work through the example of the functionality of Autodesk Inventor could help an engineer design parametric 3D items with CAD software in as rational a manner as possible and with fewer errors. The author provides recommendations on the effective management of the parameters of 3D-models in creating assembly items and 2D drawings. The use of the functionality described in the work could be of use to engineers who use methods of parametric modeling in creating standard items, optimizing and analyzing structures, developing the firm's own base of standard items that are not available in the CAD component library.

The article 'Data Processing Centers: Characteristics of Design and Operation' employs specific examples to explore the development of standard solutions in advanced construction ("Tsentry Obrabotki Dannykh," 2020). The work suggests that there are currently no two identical data centers in Russia, it being virtually impossible to use standard designs in the building of DPCs, with each new facility requiring a special approach. The article examines some of the key characteristics of the design and operation of data centers in Russia. It is suggested that the building of facilities of this kind is a new and innovative area of construction that is creating new challenges for design institutes and organizations to tackle.

Some of the related research explores issues related to the design of hardware used by enterprises.

A research study by A.G. Shchepetov (2020) explores the key aspects of the theory behind the design of devices and systems, the fundamentals of assessing the technical parameters in this process, and the key stages in it (Shchepetov, 2020). According to the author, this area performs the same role in general vocational education as the disciplines Mathematics and Physics in science education. The author stresses the importance of acquiring practical knowledge, abilities, and skills in the area of the theory, assessment of the technical parameters, and design of devices and systems. The work provides examples of solutions to standard problems in this area and relevant methodological recommendations.

A deep and valuable insight into the implementation of the design stage is provided in a work by Ya.V. Kazankina and I.V. Dudina. The authors discuss the effect of using standard design documentation on one's success at the design stage (Kazankina \& Dudina, 2020). The work describes some of the key advantages of using standard design documentation and some of the restrictions with regard to using it over again. The authors provide the definition of standard design documentation from the Town Planning Code of the Russian Federation. The authors' comparison of the costs incurred in using an original design and a standard one indicates that the use of a standard design will help achieve significant savings. The researchers' comparison of the timeframes for design based on an adopted calendar schedule indicates that it will take less time to develop the design documentation thanks to a decrease in the number of sections to be developed, as well as a shorter timeframe for passing evaluation. The authors conclude that the use of standard design documentation could help implement state programs on the construction of affordable housing, as well as projects on the building of major infrastructure facilities, in much less time and at a much lower cost.

\section{Materials and methods}

Standard design involves the use of a specific set of tools. The successful use of standard 
design solutions implies a thorough understanding of the actual logic behind the arrangement of work processes. The way a firm is going to implement its system of standard designs is, above all, linked with the needs of the client and the investor. In an investment-construction project, the client is mainly interested in the following:

- the design being high quality;

- truthful information being provided about the costs of implementing the project;

- availability of instructions on how to use and maintain the facility;

- availability of detailed schedules for the construction work;

- low cost of the design process;

- short timeframes for the design process.

In light of the objectives set for construction companies in the field of industrial construction and the fact that industrial construction is increasingly gaining momentum today, researchers have identified a set of trends in this area. Most importantly, large companies are in need of examples and analogues that could be used in design, a sort of templates to work from. This way of doing it helps enhance the quality of designs, reduce the time for completion, and narrow down the designer's options. Add to this the fact that the use of standard designs also helps narrow down one's options with regard to equipment and materials, and the effect achieved is even greater.

While the process of creating the system of standard designs (SSD) commences differently in different companies, the focus is commonly on setting the goals and objectives for the SSD, working out the concept on creating a standard design, and taking care of issues such as the structure of the project documentation, the content of its sections, and the project's finances.

Achieving the above objectives requires a set of tools adapted to the needs of present-day companies. Below is a general list of materials, methods, and solutions that could be drawn upon in creating a system of standard designs:

- technical and economical norms for construction;

- guidelines on the use of the technical and economical norms for construction developed within the frame of the SSD in forecasting the outcomes of investment decisions;

- a single database of the company's documentation on standard design (DSD);

- guidelines on the use of DSD in the design process;

- standard procurement documentation for parts, materials, and equipment, which is to be developed based on the company's needs;

- guidelines on assessing the effectiveness of standard design solutions.

- guidelines on the analysis and strategic planning of the development and use of DSD.

- guidance activity specification documents on support for, assessment of the efficiency of, and management of changes in the SSD.

In pursuing the set objectives and using the above tools, the construction company must evaluate the resulting effects, most importantly in terms of timeframes and finances.

\section{Results}

Figure 1 illustrates the author's proposed methodology for the development of a modern system of standard designs, one that will factor in current trends and future prospects in industrial construction. 


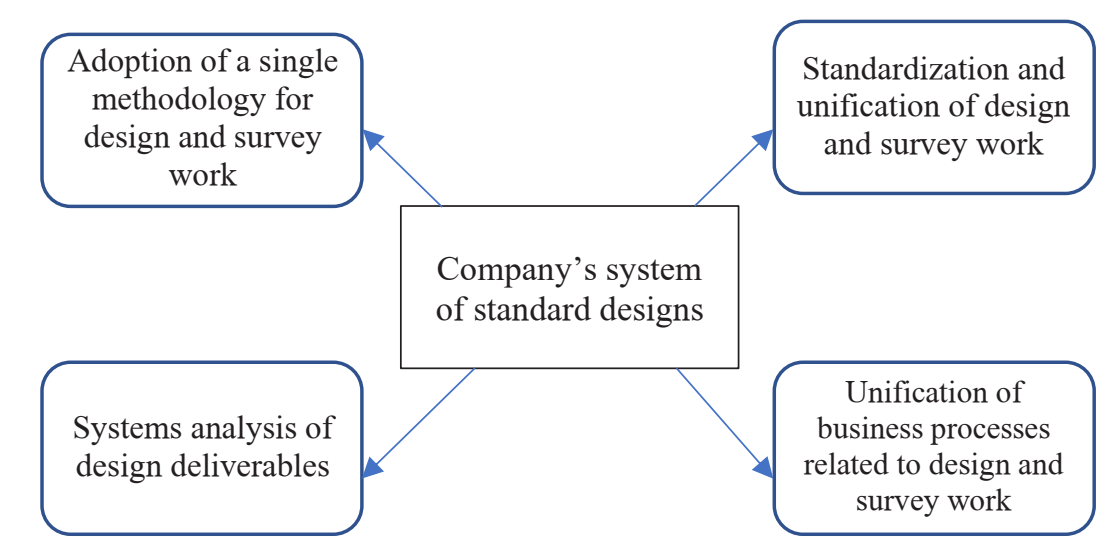

Fig. 1. A possible way to develop a company's system of standard designs.

To ensure effective work on creating the system of standard designs, one will also need to create classifiers for standard solutions that will help develop them in a timely fashion and keep pace with scientific-technical progress. This involves the following stages:

- firstly, there need to be established several levels to help organize the unification processes: Level 1 - the entire industrial facility; Level 2 - buildings and/or structures; Level 3 - constructions and joints; Level 4 - equipment, parts, and materials;

- secondly, it is the availability of standard design assignments and specifications; standard templates for design assignments; standard technical design specifications;

- thirdly, it is a collection of classifiers in the area of architectural and space-planning solutions; standard plans, sectional views, layouts of constructions and joints; standard specifications on technological and other issues, detailed layouts, plans, etc.; standard cost estimate documentation, including activity and facility cost estimate documentation;

- fourthly, the use of a system of standard designs must involve keeping track of all stages in the process - the development of space-planning documentation, design documentation, and engineering documentation;

- fifthly, the classification system must factor in the possibility of continuous development of design documentation within the frame of each systematization, which enables the system of standard designs to respond to the challenges of time.

\section{Conclusion}

Work on creating a system of standard designs is not new to the professional community of builders. Solutions of this kind used to be implemented in a systemic fashion back in the $20^{\text {th }}$ century. That being said, many large corporations, including Rosneft, Gazprom, and Transneft, have started on this path just recently - only in the previous decade (Spektor, Ivanov, \& Vasin, 2020). Of interest are the results achieved by some of the companies at the cutting edge of design. For instance, Shell has posted a 30\% drop in expenditure on the purchase of materials and parts; a $50-80 \%$ drop in warehousing expenditure; a $5 \%$ drop in the cost of facilities of permanent construction; a 13\% decrease in the timeframe for completion of a construction project. In another example, Gazprom has developed, ratified, and implemented since 2005 as many as 585 regulatory documents and recommendations, with the effect from the implementation of the standards constituting 11.4 rubles per one ruble of expenditure.

Thus, the creation of a corporate system of standard designs is a promising line to pursue, as it is aimed at the following: optimization of requirements for design, processes, and 
methodologies; standardization of technical specifications and unification of materials and equipment; unification and standardization of engineering and design solutions for surface facilities and various elements of surface infrastructure based on the choice of the more effective solutions; creation of a technological foundation for optimizing expenditure in permanent construction. On the other hand, some of the key common effects achieved by companies as a result of implementing a system of standard designs include the following: shorter design timeframes and lower design costs; improved quality of design deliverables; optimized engineering solutions and capital and operating expenditure; redundant engineering solutions being dropped; the company pursuing a single engineering policy; requirements for materials and equipment being unified; a foundation being laid for entering into price-list agreements on materials and equipment.

\section{References}

1. V. V. Taberko, D. S. Ivaniuk, V. V. Kasyanik, V. A. Golovko, K. V. Rusetski, D. V. Shunkevich, N. V. Grakova, Design principles of integrated information services for batch manufacturing enterprise employees. Proceedings of Open Semantic Technologies for the Design of Intelligent Systems: International Scientific-Technical Conference, 215-224 (Minsk, Belarus: Belarusian State University of Informatics and Radioelectronics, 2019)

2. O. L. Sorokin, I. G. Sidorkina, Intellectual variation by penalty coefficients in the algorithm in constructing the contour of the enclosing structure of the heat network in the environment of the building CAD, Proceedings of Open Semantic Technologies for the Design of Intelligent Systems: International Scientific-Technical Conference, 167171 (Minsk, Belarus: Belarusian State University of Informatics and Radioelectronics, 2018)

3. V. K. Demchenkov, A shift to the use of standard designs in construction as a priority area for the development of the construction sector for the period through to 2030. In Proceedings of Present-Day Trends in the Development of the Economy and Education in a Region: 4th Regional Research-to-Practice Conference, Velikiye Luki, December 12-13, 2019, 124-128 (Moscow, Russia: Mir Nauki, 2020)

4. I. V. Berezhnaya, Formalizing a model of an intelligent system for selecting standard algorithms in the design process, In Proceedings of Basic and Applied Research: Topical Issues, Achievements, and Innovations: 30th International Research-to-Practice Conference, in two parts, 122-125 (Penza, Russia: Nauka i Prosveshchenie. 2020)

5. M. A. Baldin, A. V. Korolev, D. V. Kutuzov, The use of BIM technology during the stage of designing architectural and constructive solutions for standard buildings, In 9th All-Russian Festival of Science: A collection of reports (in two volumes), 332-337 (Nizhny Novgorod, Russia: Nizhny Novgorod State University of Architecture and Construction, 2020)

6. E. A. Petrakova, The use of techniques of effective design in creating parametric $3 D$ models using the capabilities of CAD software, Spravochnik. Inzhenernyi Zhurnal s Prilozheniem, 3, 51-56. (2020)

7. Data processing centers: Characteristics of design and operation, AVOK, 1, 56-59 (2020)

8. A. G. Shchepetov, Fundamentals of the design of devices and systems: A textbook and practical reference guide (Moscow, Russia: Urait, 2020) 
9. Ya. V. Kazankina, I. V. Dudina, The effect of using standard design documentation on the design stage, In Proceedings of Young Thought: Science, Technology, and Innovation: 12th (18th) All-Russian Scientific-Technical Conference for Students, Graduate Students, Postgraduate Students, and Young Students, 15-17 (Bratsk, Russia: Bratsk State University, 2020)

10. Yu. I. Spektor, A. N. Ivanov, E. S. Vasin, On the experience of OOO Gazprom Proektirovanie examining the design documentation on PAO GAZPROM's facilities under major renovation, Gazovaya Promyshlennost', 1, 116-120 (2020)

11. G. Kozlov, et al. E3S Web of Conferences 175, 12015 (2020) do: $10.1051 / \mathrm{e} 3$ sconf $/ 202017512015$ 